\title{
Breve exposição ao Soleil
}

\author{
Maria Lúcia de Souza Barros Pupo
}

ede paulistana da Cartoucherie no SESC Belenzinho, noite quente de outubro de 2007, pouco depois dos aplausos finais aos Éphémères. Em meio aos comes e bebes, mesclados ao entusiasmo barulhento dos espectadores, circulam alguns membros da trupe, prontos para começar novas trocas com o público, dessa vez sem o invólucro dos personagens.

Maurice Durozier - que, nos fez descobrir, entre outros, Manolo em férias à beira-mar e o jardineiro Mathurin - revela seu desejo de entrar em contato com os estudantes de teatro da Universidade de São Paulo. Consultado sobre a natureza do encontro, opta por uma experiência prática. Anos antes já havia conhecido outros pedaços do Brasil: em Pernambuco e no Ceará, junto a George Bigot, seu colega no Soleil, vivera experiências de improvisação teatral com habitantes de vilarejos interioranos, por ele qualificadas de extraordinárias.

Pertencente à quinta geração de uma família de atores ambulantes que apresentava seus espetáculos percorrendo a Europa em carroças, Maurice reivindica suas raízes populares e o prazer das descobertas provenientes do próprio fazer teatral. Entre 1980 e 1991 atua em criaçōes famosas do Théatre du Soleil, como Richard II,
Henry IV, L'Histoire Terrible mais Inachevée de Norodom Sihanouk, Roi du Cambodge e L'Indiade ou L'Inde de leurs Rêves. Em 1992 afasta-se do grupo para fundar sua própria companhia, Les Voyageurs de la Nuit, mas em 2002, chamado por Mnouchkine para assessorá-la por ocasião da organização de um estágio, Maurice regressa ao grupo. Participa então da encenação de $L e$ Dernier Caravansérail e agora de Les Éphémères.

Um workshop por ele coordenado e dirigido aos estudantes do Departamento de Artes Cênicas e da Escola de Artes Dramáticas é então previsto e organizado para o dia 17 de outubro. Seu título: $O$ ator criador. A imaginação é um músculo que se trabalha. Durozier se propõe a "transmitir as bases das leis nas quais repousam os métodos de investigação dos atores do Théâtre du Soleil" através de determinadas noçôes-chave, entre as quais menciona as emoçōes, o corpo, a imaginação e o concreto.

Cerca de quarenta estudantes, roupas de trabalho, visivelmente ansiosos para iniciar, sentados em círculo no chão, ouvem atentamente os comentários sobre a seqüência prevista e as primeiras instruções. O olhar vibrante e profundo, a fala pontuada por longas pausas nas quais parece elaborar o que vai dizer a seguir, uma

Maria Lúcia de Souza Barros Pupo é professora titular do Departamento de Artes Cênicas e do programa de Pós-Graduação em Artes Cênicas da ECA-USP. 
notável leveza na movimentação e alguns diálogos mudos com a tradutora marcam o estilo de coordenação do visitante.

Uma série de exercícios à primeira vista simples, envolvendo atenção ao outro, a concentração e a necessária tranqüilidade para agir dentro do grupo começa a ser proposta.

O primeiro deles: dizer o próprio nome, um depois do outro, sem atropelos, escutando os parceiros. A partir da terceira tentativa, o desafio é compreendido e a performance começa a se depurar: o tempo se dilata, a afobação arrefece. Nas rodadas seguintes, ao invés do próprio nome, é o do vizinho da direita e depois o da esquerda que deve ser enunciado. A atenção é imediatamente trazida à berlinda e a preocupação consigo mesmo se evidencia como obstáculo para a apreensão do todo.

A concentração e a percepção sensível do parceiro continuam a ser convocados na proposta seguinte. Os membros de sub-grupos formados aleatoriamente com 2 até 6 pessoas devem, exatamente ao mesmo tempo, sem qualquer planejamento e de modo tácito, ter a iniciativa de sair da roda, andar dentro dela e voltar ao lugar de origem. Como já havíamos presenciado em momentos anteriores, a ansiedade e o desejo de manifestar iniciativa prestam seu habitual desserviço aos atores; muitas vezes retomado, o desafio é satisfeito apenas em algumas - poucas - rodadas. Quando isso se dá, no entanto, o momento em que ocorre a faísca do agir junto se torna palpável, sem margem para dúvidas. Para além da fábula, da situação, do personagem, estamos diante do prazer puro da performance, da evidência do acordo implícito, da conivência que passa pela pele e pelo olhar, se traduzindo, sem preparação, na magia do movimento sincronizado.

Diferentes modalidades de acordo tácito foram trazidas à tona. Mais alerta, mais disponíveis em relação aos parceiros, os participantes agora estão, pode-se dizer, mais presentes na sala de trabalho; a escuta do outro e a calma indispensável para que ela se dê deixam de ser noções vagas e começam a se tornar tangíveis.
Maurice fala pouco, faz perguntas, pede que as pessoas concluam por si mesmas.

A etapa seguinte caracteriza aquilo que Ariane denomina o "estado de urgência" do ator em representação. O espaço é dividido em quatro quadrados com a ajuda de fita-crepe colada no chão. Dentro de cada um é colocado um pedaço de papel onde se lê: "amor", "asco", "medo", "fúria"; mais tarde dois deles são substituídos por "dor" e "deslumbramento". Não se anuncia de antemão aquilo que estará em jogo; visa-se a descoberta dos participantes. A cada experimentação, três a quatro atores se apresentam como voluntários para viver a emoção designada no espaço. Espera-se do ator que entra em cena que já esteja em determinado estado, sem qualquer aquecimento prévio particular; não há personagem ou situação de apoio.

Várias combinações são possíveis; as relações entre os atores se dão tanto entre diferentes quadrados, quanto dentro da mesma casa. "No teatro precisamos do outro para existir", lembra nosso ator-diretor. As regras não são explicitadas a priori, mas apenas à medida que se tornam necessárias: o toque e a fala estão banidos. O corpo inteiro é assim convidado a sentir as vibraçôes da emoção em pauta; relações de atração, repulsa e empatia devem se manifestar de modo concentrado e não verbal.

A música se faz presente durante toda a duração do trabalho, através de diferentes CDs; melodias gregas, armênias, turcas e canções francesas populares transformadas em surpreendentes flamengos fornecem a variedade de pulsações que sustenta a exploração dos atuantes. Instruções precisas no sentido de se ouvir a música e de se deixar guiar por ela durante o exercício são apresentadas e reiteradas.

Em algumas situações Maurice pede que os atores vivam o "estado emocional" mantendo o olhar sempre dirigido ao público: não há quarta parede, somos ainda mais envolvidos, pois é diretamente para nós que estão sendo endereçados os sentimentos em questão. $\mathrm{O}$ desafio que se apresenta é claramente circunscrito: sem qualquer preparação, justificativa, ou 
gradação progressiva, o participante, apoiado apenas pela música e pela relação com o outro, é convidado a se tornar disponível, a impregnar-se de um determinado estado emocional, na ausência de qualquer fábula. Aqueles que se mantêm na platéia, solidários, também fazem seu percurso estático dentro das propostas de experimentação de diferentes sentimentos: examinam atentamente as soluções apresentadas, são contaminados pela exposição seguida dos parceiros que tentam, com um mínimo de indicações, instaurar e manter determinados estados emocionais, incluindo a transição entre eles.

"Não procure, não force, deixe acontecer, deixe o estado vir, deixe-o invadir você" é a instrução recorrente. Fundem-se assim os princípios que haviam orientado os momentos iniciais do workshop com os desafios da criação dos estados emocionais. Pede-se ao ator que seja transpassado por determinados sentimentos, mas ao mesmo tempo se solicita que não ceda às facilidades do gesto que procura explorar. $\mathrm{O}$ não movimento, o estar presente, a apreensão de tudo o que acontece na cena, a não antecipação são enfatizados. Deixar de fazer a qualquer custo, e sobretudo estar atento ao companheiro, são algumas das mais relevantes indicaçōes, devidamente retomadas. "O ator deve inicialmente escutar, em seguida saber parar, calar-se, aceitar a imobilidade", princípios caros à própria Ariane Mnouchkine (Pascaud, 2005, p. 66), são trazidos à baila de diferentes maneiras, mais ou menos diretas, ao longo do workshop.

Atento a que todos os componentes do grupo tenham a experiência do exercício, Maurice não oculta seu entusiasmo quando as emoções passam a habitar o espaço e atingem a platéia. Impressionada com a irrupção de intensidades emocionais que, desde sua aparição, já são contidas por regras que lhes atribuem algum contorno formal, observo, no intervalo que se segue, os comentários entusiasmados dos participantes.

Uma breve incursão à aprendizagem pela via da cópia é o que se observa na seqüência. Maurice faz referências às viagens do Soleil à Índia e exemplifica como o teatro Kathakali e outras formas tradicionais do espetáculo vivo naquele país aliam a expressão facial, e ainda mais especialmente, o olhar, aos mudras, signos executados com gestos das mãos.

Simultaneamente, experimentamos imitar cada uma das atitudes assumidas pelo atordiretor; copiamos, entre outros, o mudra da flor de Lótus. O desenho nítido da postura, a precisão do gesto, a força e o direcionamento claro do olhar são demonstrados por Maurice, pontualmente erigido como modelo a ser imitado pelos componentes do grupo. Dor, compaixão, heroísmo, medo, fúria, serenidade, riso e, contendo todos eles, o sentimento do amor, constituem os vetores da representação, conforme ele esclarece.

$\mathrm{O}$ que se tem em vista na relação com os estudantes em formação é uma apreensão necessariamente ligeira, mas vivida corporalmente, de uma codificação dos sentimentos, instaurada no âmago de manifestaçôes cênicas indianas. O princípio agora se inverte: copia-se uma forma e dessa cópia emerge a emoção buscada. Inicia-se então o percurso final do trajeto traçado para o workshop: Macbeth passa a ser o eixo da experiência estética. São distribuídos vários exemplares do trecho a ser trabalhado; estamos no primeiro ato, cena V: entra Lady Macbeth lendo uma carta de seu marido e logo em seguida aparece o mensageiro anunciando que Duncan, rei da Escócia chegaria naquela mesma noite.

O dispositivo cênico remete de imediato ao minimalismo hierático de alguns espetáculos do Soleil Uma cortina preta de $3 \mathrm{~m}$ de altura por $5 \mathrm{~m}$ de largura, paralela à parede, mas afastada dela; entre a cortina e o público, um grande tapete. A potente sonoridade - poder-se-ia dizer "mediterrânea" - de uma música impregnada de percussão e cordas povoa a ampla sala de ensaios. A situação é nova, o espaço é outro, mas se identifica no dispositivo armado uma atmosfera de expectativa, de solenidade similar àquela que se observava nas encenações de Shakespeare realizadas pelo Théâtre du Soleil ao longo dos anos de 1980. 
Assim como tinha ocorrido em uma cena de Éphémères, o vazio impressiona e comove. Em determinada passagem deste último espetáculo, desfilam diante do público os praticáveis mobiliados que, pouco antes, haviam sediado confrontos, decepções, alegrias, de diferentes personagens, agora ausentes. Embora nesse momento eles não estejam mais lá, dentro das ambientações que passam diante de nós ainda ecoam as emoçôes recentemente representadas. De modo semelhante agora, dentro da universidade, a visão de um espaço de experimentação configurado com tão poucos recursos, carrega consigo fortes ressonâncias de encenações antológicas da trupe. A lembrança delas e a perspectiva de que o grupo de jovens estudantes vai se deter sobre a "peça escocesa" já faz antever desejos e paixões avassaladoras, lutas pelo poder, quedas inevitáveis. Logo mais esse espaço estará habitado.

O caráter épico do fazer teatral do Soleil se manifesta em vários aspectos da prática à qual tivemos acesso. Assim como a música de Lemêtre é onipresente tanto em ensaios, quanto nos espetáculos, aqui também ela é essencial; caracteriza os climas, estabelece a pulsação das cenas, sustenta e conduz o trabalho dos atores.

As regras são apresentadas. Distribuídos em sub-grupos, todos os participantes passam pela experiência: sobre o tapete, Lady Macbeth; atrás da cortina, escondido num primeiro momento e entrando apressado logo depois, está o mensageiro. Fora do tapete, à esquerda, dois atores lêem o texto. À semelhança dos procedimentos do bunraku, o desafio é a dissociação entre a palavra por um lado, e a ação e o movimento por outro. Nenhuma identificação, nenhuma tentação realista: aquilo que é dito ganha uma densidade singular, como se as palavras tivessem ocupado o primeiro plano.

Maurice explicita sua posição contra o ato de decorar o texto, destacando os efeitos de automatismo que ele acarreta. O que se busca é explorar o fragmento de Macbeth sem preparação anterior, a partir dos estados emocionais que atravessam os personagens. Uma outra variante é também testada: os atores-personagens repetem em eco as frases lidas, como se tivessem sido ditas por um ponto altissonante. Como parte do trecho em pauta é constituída pela carta enviada por Macbeth à esposa, a investigação coletiva contribui também para que o grupo compreenda a dimensão da narração no teatro. Entre os atores leitores e os que emprestam seus corpos aos personagens instaura-se uma relação de escuta recíproca que se torna o centro de interesse da cena.

Os sub-grupos se sucedem e as dificuldades se manifestam. Maurice interpela os atores acerca das informações reveladas pelo texto: onde eles estão, qual o efeito da carta sobre Lady Macbeth, de onde vem o barulho do corvo, como está a respiração do mensageiro ao chegar, como ele saúda sua senhora e assim por diante. Momentos de vacilação entre os jovens atores ocorrem quando ele os questiona acerca de detalhes da intriga, nem sempre perfeitamente dominada. Em outras ocasióes, Maurice, empolgado, faz comentários sobre a necessidade de maior intensidade, mas não formula instruções precisas. Outras vezes ouvimos dele frases mais claras como "sinta com o corpo inteiro", "mais forte; deixe o estado emocional invadir você". A platéia, apesar de altamente envolvida, não é interpelada diretamente.

Tudo o que ocorre no espaço delimitado pode ser incorporado pelo jogo. Uma porta bate, fortuitamente fechada pelo vento e passa a fazer parte da cena, sendo usada pelo mensageiro nas retomadas subseqüentes. Uma atriz que faz Lady Macbeth manifesta estar sentindo vertigens e pede para sair; Maurice insiste e solicita que o mal estar seja integrado ao personagem, o que acaba sendo vivido como uma vitória pessoal por parte da jovem.

Há momentos em que aquela curta passagem de Shakespeare ganha envergadura e temos então a impressão de assistir ao fenômeno descrito pela própria Mnouchkine: "Penso que o texto é como uma secreção; quando [o espetáculo] está bom, é que o texto se torna a secreção do corpo" (Féral, 1998, p. 222). 
Roda de encerramento do encontro. O coordenador é questionado sobre sua história pessoal, as influências sofridas, as recomendações que gostaria de deixar aos estudantes em formação. Em seu discurso final, ele ressalta enfaticamente a importância das leituras e do cinema, além da freqüentação do próprio teatro, como ingredientes indispensáveis ao desenvolvimento da imaginação, "músculo" primordial ao trabalho do ator.

Concentrada num período de poucas horas, a prática que se deu a conhecer não poderia ser precipitadamente sintetizada como "o trabalho do Soleil". Entre outros fatores que justificam essa impropriedade, cabe lembrar que a multifacetada e complexa trajetória do grupo não se traduz em um modo unívoco de fazer face aos desafios da cena. Defrontar-se com o texto trágico de Ésquilo ou formular em uma poética resultante de improvisaçōes, o percurso atual de um personagem em busca de referências sobre seu passado - como vimos no último espetáculo - implicam atitudes distintas diante da encenação e da preparação do ator, que não se pode catalogar de modo simplista. No entanto, é inegável que pudemos ter acesso a alguns dos princípios que regem as qualidades desejadas para o desempenho dos atores da trupe. Não seria o caso de inferir uma organização sistemática do trabalho, nem tampouco um método de atuação, visto que não houve recorte de problemas específicos ou cuidado particular com a gradação das dificuldades. Todos os aspectos da atuação foram tratados ao mesmo tempo, dentro de uma situação precisamente delimitada. O corpo do ator não parece constituir uma preocupação tida como primordial ou mais intensa do que as demais; a imaginação e a atenção concentrada é que impulsionam as reações corporais. Vigora a noção de que o ator se doa ao personagem, se deixa penetrar por ele.

Um fio condutor tangível perpassa certamente o encontro na USP como um todo: é o exercício da escuta do outro que possibilita esse tão almejado estado de disponibilidade. "Se deixar fazer, deixar as coisas se produzirem, receber, ainda e sempre, escutar. E o ator escuta com tudo, com toda sua pele. Quando digo com sua pele, isso quer dizer que ele não escuta somente as palavras, mas também como ele diz as palavras. Ele recebe. Ele traduz, ele traduz o suor do outro. É fundamental" (Féral, 1998, p. 213).

Misto de ator, diretor teatral e pedagogo naquela circunstância singular, Maurice se despede do grupo sensivelmente tocado pela experiência. Ouvem-se aplausos. Olhares brilhantes, rostos serenos, sorrisos sutilmente esboçados, poucas palavras, começamos lentamente a nos separar. Havíamos penetrado, mesmo que de leve, nas emanações do Soleil.

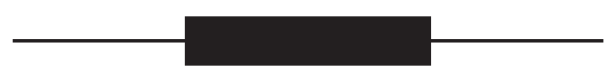

\section{Referências bibliográficas}

PASCAUD, Fabienne. Ariane Mnouchkine. Entretiens avec Fabienne Pascaud. L'art du present. Paris: Plon, 2005.

FÉRAL, Josette. Mise en scene et jeu de l’acteur. Montréal: Lansman, 1998. 